\title{
LAS ORACIONES BÁSICAS Y LA PUNTUACIÓN DE LOS COMPLEMENTOS ACCIDENTALES
}

Santos Conde Lucero ${ }^{1}$

\section{RESUMEN}

El presente artículo ofrece un estudio de las oraciones básicas del español y tiene como marco de referencia a la teoría de la sintaxis según la lingüística de la comunicación y a la gramática textual. Una oración básica contiene la idea esencial. Se caracteriza por tener sujeto, núcleo oracional y complemento. El núcleo oracional lo conforma un verbo transitivo o intransitivo. Existe una sola diferencia. La oración con verbo transitivo lleva objeto directo, mientras que la oración con verbo intransitivo, no. Respecto a este último, el verbo puede ir solo o acompañado de un adverbio o de un sintagma preposicional. Pero las dos formas se escriben sin comas. Finalmente, la oración, motivo del presente trabajo, se aborda en su doble función: como función informativa y como función representativa.

\section{INTRODUCCIÓN}

El objetivo es orientar en la construcción de oraciones básicas, como medio para mejorar la claridad de las ideas en un texto escrito. A raíz de la observación de algunos reportes científicos se ha detectado algunos inconvenientes para adecuar los resultados numéricos a la forma lingüística y ésta a las capacidades de interpretación de los lectores. Respecto a la forma lingüística, no ha sido difícil deducir dos problemas que afectan a los autores: el desconocimiento de las reglas para organizar las oraciones básicas y, por otra parte, la carencia de estrategias procedimentales para el correcto uso de la coma, pues, los signos de puntuación son los indicadores que orientan la recuperación del mensaje cuando es

'Magister en Docencia Universitaria. interpretado por el lector.

La redacción de los informes de investigación, luego la preparación de reportes para la publicación en revistas especializadas no son tareas sencillas. El autor debe tener referencia mínima de sintaxis de la oración y conocimiento de la normativa del idioma. Estas capacidades le permitirán convertir aquellos resultados expresados en cifras y carentes de contenidos en un texto correctamente articulado.

No se trata entonces de adjuntar al análisis de los resultados, los objetivos y la hipótesis establecido en el proyecto. El criterio de unidad y coherencia va más allá de un simple cúmulo de partes. La primera acción del investigador que escribe está relacionada con la intención. Como informante, no puede ignorar a su 
destinatario, a quien o a quienes va dirigido el trabajo y, en ese afán, busca la claridad del mensaje y tal propiedad se logra con la construcción correcta de las oraciones.

El autor está obligado a escribir dentro del marco académico que le asiste. Cuenta con los resultados de la investigación que realizó, entonces necesita redactar un reporte. Allí nuestra intervención, no para enseñarle a escribir, sino para brindarle apoyo y supere las dificultades de escritura, hasta concluir con éxito la tarea emprendida.

La competencia comunicativa de los que escriben no es uniforme. Los casos que obstaculizan el acto tampoco son los mismos. Pero la coincidencia en la mayoría de ellos radica en la dificultad para el control simultáneo de los siguientes hechos: precisar las ideas que necesitan, luego disponerlas correctamente, encontrar las palabras exactas, construir gramaticalmente la oración y, finalmente, escribir en el papel.

Promover la reflexión a partir de los errores ayuda a tomar consciencia. Tal acto requiere que se escriba en dos momentos, primero dirigido a un lector, por decir, que no conoce el tema, luego, en una segunda instancia, releer la escritura, corrigiendo los errores, con la observación de un lector crítico. Debe ser este texto, el que se dirige a otro lector.

En la fase final, la razón y la imaginación contribuyen a dar forma definitiva al trabajo. Así concluye la etapa de pretexto, con una extensión determinada y el tema debidamente desarrollado.

Para un autor que ha llegado a tomar consciencia, la tarea aún prosigue. Es así cómo, vuelve a tomar decisiones para ver si el texto acabado necesita de una relectura crítica de alguien. Si se encuentran errores, no dudará de la reescritura, entonces, tachará, suprimirá, pulirá, a fin de valorar sus ideas. La etapa de textualización concluirá, una vez el mensaje escrito alcance el propósito ansiado.

Retornando a la oración, esta unidad gramatical fue objeto de estudio en el pasado y, por cierto, del modelo clásico, del modelo estructural y del modelo generativo y también de otras orientaciones posteriores que la consideran una estructura funcional, jerárquicamente organizada. En la actualidad, siendo el objeto de estudio el texto, la oración no ha desaparecido, más bien, existe un redescubrimiento que bien merece tomarlo en cuenta para efectos de producción e interpretación.

Uno de los procedimientos a tener en cuenta corresponde a la aplicación de la teoría sintáctica, en la organización de las oraciones; pero no sólo ubicando correctamente el sujeto, verbo, objeto directo y objeto indirecto, tampoco, ampliando la construcción, mediante los complementos accidentales o circunstanciales o aplicando otro procedimiento relacionado con la puntuación, como el uso de la coma en ese tipo de oraciones, sino adecuando al texto como función informativa y como función representativa.

Estas razones obligan a las personas que investigan a revisar también las teorías de sintaxis existentes en la actualidad, a fin de optimizar la escritura de sus ideas que desea comunicar. La representación de las ideas implica configurar un sintagma o un conjunto de sintagmas, pensando en lo que imaginan que el lector o los lectores 
desconocen. Como se ve, escribir es un acto consciente.

El acto de la comunicación escrita surge en la mente del emisor, impulsado por una idea, la cual es adecuada en una forma determinada que se llama oración, la misma que es expresada en forma oral o escrita. Sólo que ningún hablante escribe como habla ni habla como escribe. En la comunicación oral, tales ideas se dicen de muchas maneras; en la comunicación escrita, también; pero la que realmente informa es una sola y se llama oración básica, como la que sigue:

\section{(01) Rigoberto entrega un reporte a la secretaria.}

1.a A la secretaria Rigoberto entrega un reporte.

1.b Rigoberto un reporte entrega a la secretaria.

1.c Entrega a la secretaria un reporte Rigoberto.

1.d.Un reporte entrega Rigoberto a la secretaria.

Las oraciones (1.a), (1.b), (1.c) y (1.d) dicen lo mismo que [01], pero no son las más adecuadas. La oración más adecuada y que realmente informa es (01). Esta unidad sintáctica ideal, formalmente, tiene un orden lógico. Las categorías gramaticales que la conforman están ordenadas de la siguiente manera: Nombre (N) y Verbo (V) respectivamente. Esta última categoría recibe la modificación de un complemento directo y un complemento indirecto.

Por otra parte, una oración básica no sólo está conformada por categorías verbales, sino, al mismo tiempo, estas intervienen como funciones, por lo tanto, según la corriente funcionalista, aquellos segmentos sintácticos se desempeñan como sujeto, núcleo oracional y objeto.

La escritura de una idea esencial implica

'D'TNTRONO, Francesco: Sintaxis generativa del español: evolución y análisis, Pág.11 entonces disponer las palabras, siguiendo aquel orden lógico. Por lo general, las personas que escriben no reparan en él, tal vez, porque no tienen idea de sintaxis. Esta disciplina no sólo teoriza las construcciones, sino brinda las reglas para su correcta organización. Para el caso de las oraciones del español ha establecido el siguiente orden: nombre, verbo, complemento directo y complemento indirecto.

$$
N+V+C D+C l
$$

Según Francesco D'ntrono, "la sintaxis es el conjunto de reglas y principios que establece cómo se escriben las frases..." 1. El término/regla/, en lingüística hay que entenderla simplemente como sinónimo de /orden/. La sintaxis, en consecuencia, nos permite decir que Rigoberto entrega un reporte a la secretaria, es una oración correcta, porque las palabras están dispuestas en orden $(\mathrm{N}+\mathrm{V}+\mathrm{OD}+\mathrm{Ol})$ y no Entrega a la secretaria Rigoberto un reporte. Al igual que $D$ 'ntrono también comparten esta idea Roger Hadlich, Heles Contreras, María Luisa Rivero e Ignacio Bosque.

Sin embargo, Salvador Gutiérrez, basado en la lingüística de la comunicación, observa que el modelo estructural y el modelo generativo se limitan a la descripción de las palabras y a la intervención de las reglas para la organización e interpretación de las oraciones.

Teniendo como fundamento los principios que plantea $\mathrm{D} . \mathrm{H}$. Hymes, ofrece una nueva alternativa, que supera a la antigua competencia lingüística y la denomina "competencia comunicativa". Según él, ésta contiene dos partes estrechamente vinculadas: "saber y saber hacer". 
Saber implica tener información. Significa poseer cierto conocimiento de la sintaxis de una lengua, así como de las normas ortográficas. En cambio, saber hacer se refiere a la habilidad comunicativa de la persona que escribe, quien hace uso de su conocimiento sintáctico para dar forma lingüística a las ideas que necesita expresar. Además, Salvador G. establece la siguiente subdivisión:

a. Competencia lingüistica: fonologia, Morfología, sintaxis y Lexicología

b. Competencia periférica: Textual, Psicolingüistica, sociolingüistica y Etnolingüistica o cultural.

c. Competencia pragmática.

A! ocuparse de la lingüística de la comunicación, establece diferencias entre competencia lingüística, competencia comunicativa y competencia sintáctica. Esta última es la que posibilita el buen desempeño para la escritura. Hace de quien escribe un ser consciente, al reconocer que la sintaxis que utiliza cumple doble función: función representativa y función informativa.

Respecto a la función representativa de las oraciones, en mutua concordancia con muchos gramáticos, señala que una oración se organiza en tres niveles funcionales:

(a)Funciones formales: sujeto, predicado, objeto directo, objeto indirecto, complementos

(b)Funciones semánticas: Agente, paciente, instrumento...

(c)Funciones informativas: tema, rema, foco...

Los niveles (a) y (b) constituyen la función

"CASADO VELARDE, Manuel: Introducción a la gramática del texto del español, Pág. 10. representativa del lenguaje. Pues, a través de la función formal y función semántica, el que escribe refleja, copia, representa situaciones, procesos, acontecimientos... Por lo tanto, si éste desea comunicar un mensaje por escrito, inicia la operación con una representación mental, luego, elige una organización sintáctica determinada. En él, previamente, surgen las ideas, luego, tales ideas las convierte en formas sintácticas que se llama oración y período.

La conversión del nivel semántico al nivel sintáctico no es tan sencillo como se podría imaginar. Frecuentemente, las personas que escriben realizan esta operación, aunque sin mayor control. Al no tener una información teórica suficiente de sintaxis, su metacognición, por no decir nula, resulta insuficiente. Situación muy distinta en el caso de los expertos, pues ellos son conscientes de su propio acto de escribir.

La otra etapa corresponde a la configuración de la secuencia de ideas en secuencia de oraciones, hasta conformar el texto y tal realización se conoce como función informativa. Sucede que al convertir aquellas y luego organizarias no reparan en los asuntos de coherencia, siendo ella una de las propiedades del texto que sostiene las redes semánticas. Casado Manuel Velarde sostiene que texto es "una parte de la gramática de un idioma... que describen los hechos idiomáticos que exceden el ámbito oracional..."?

La otra propiedad del texto es la cohesión y en ella se sujeta la puntuación y entonación. Se entiende a la puntuación como uno de los mecanismos formales que ayuda a precisar lo que queremos informar, tal como deseamos que interpreten los lectores. 
Sin esas consideraciones, se supone que un texto está organizado mecánicamente por un conjunto de oraciones y no cumple con una de las cualidades que debe tener un mensaje: la claridad.

Como queda demostrado, la competencia textual ha desplazado a la competencia lingüística. En el plano de la sintaxis, supera los límites de la oración, al dar prioridad a las relaciones interoracionales, de esta manera, las oraciones conforman una red de naturaleza semántica, y cada cual se cohesiona mediante mecanismos de naturaleza formal y, como dijimos, uno de ellos es la puntuación.

Hablar de una sintaxis superior a la oración supone también que las personas que escriben deben tener dominio de los conectores textuales, aún más, deben saber el significado de cada cual, para su uso apropiado.

A pesar de estos avances, una de las mayores dificultades que obstaculizan la escritura de un texto sigue siendo la construcción sintáctica y la puntuación. Respecto al primer obstáculo, una alternativa es reforzar la teoría de la oración básica y ejercitarse en la organización de la misma, aplicando las reglas de producción correspondientes. En cuanto al segundo obstáculo, corresponde al uso apropiado de la coma para separar los circunstanciales en oraciones cuyos complementos no son básicos, sino accidentales.

\section{TEORÍAS DE LA SINTAXIS SEGÚN LA LINGÜÍSTICA COMUNICATIVA}

El término sintaxis proviene de dos voces griegas, /syn/ que significa "con", y /taxis/

${ }^{3}$ CONTRERAS, Heles. El orden de las palabras en español, Pág. 17 que significa "orden". Un concepto aproximado podría ser el nivel de la lengua que estudia el orden y funcionamiento de las palabras que conforman una oración. La oración no sólo es el signo modelo de la comunicación lingüística. Heles Contreras va más allá, al sostener que: " el hablante trata de traer a la conciencia del oyente ciertas unidades comunicativas que considera ausentes en el momento de la comunicación..." ${ }^{3}$. Reconoce que la oración tiene dos elementos importantes: la cima melódica y el orden lineal. La cima melódica permite distinguir cuándo la oración es "una información dada", y cuándo, una información "nueva".

En cuanto al orden lineal, se refiere a la disposición de las palabras que se constituyen en sintagmas y estos, en oración. Tal como se ha expuesto en la parte introductoria.

Una oración básica es aquella construcción que, no sólo tiene un orden lógico, sino que lleva un verbo transitivo o intransitivo. Saber distinguirlos es importante para la puntuación, pues, el uso de las comas en un texto escrito es un problema de estructura.

Raúl Ávila se reserva la expresión "oración básica" y prefiere el nombre "oración determinativa" para identificar a la unidad que contiene la idea esencial. Sostiene que: "la esencia de la idea va sin coma". ¿Qué se entiende por esencia de una idea?. Es lo que pensamos sobre el objeto, ser, fenómeno o situación. En gramática textual es la información nueva, lo que no se conoce y que se identifica como rema. Según $\mathrm{H}$.

Contreras, lo opuesto a rema es el tema que es "lo que existe", "lo viejo", "lo que se conoce", la información dada. Matthesius 
precisa que el tema "es aquello conocido y a partir del cual el hablante procede en su discurso" y rema es "lo nuevo". Halliday y Matthiessen definen que "tema es el elementos que sirve como punto de partida del mensaje; es lo que sitúa y orienta la oración dentro de su contexto." Por lo tanto, el tema y el rema son componentes interpretativos que contiene un texto.

El presente trabajo se centra sólo en uno de los problemas que afecta al que escribe y es la transformación de una idea en oración, aplicando las reglas sintácticas.

Partimos de la premisa siguiente: si una idea se traduce en una oración, entonces, el número de oraciones variará proporcionalmente en función al número de ideas. El problema radica en saber representarlas, mediante la distribución de los sintagmas, de manera correcta.

Un sintagma se organiza en torno a un núcleo. Los adjuntos que se anteponen o posponen al núcleo son sus modificadores. Según la clase de palabra que desempeñe como núcleo, el sintagma recibirá un nombre determinado.

Si el núcleo es un nombre, el sintagma será nominal, si es un adjetivo, el sintagma será adjetivo; si es un verbo, el sintagma será verbal o si es un adverbio, el sintagma será adverbial. En esta ocasión, no es el caso ocuparnos de estos temas. Pero, como ilustración formemos un sintagma nominal con los términos <un > y <lápiz >.

Al núcleo (N) <lápiz> anteponemos el modificador directo (MD) $<\mathbf{u n}>$, de modo que las dos palabras formen el sintagma nominal (SN): <un lápiz>. Para mayor visualización, dicho sintagma se representa en el siguiente diagrama:

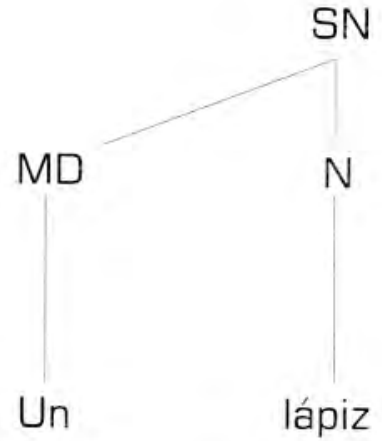

Los sintagmas no representan ideas. La esencia de las ideas se manifiesta mediante oraciones que están estructuradas de la siguiente manera: Nombre, verbo, objeto directo y objeto indirecto.

Existen teorías que se refieren a la transformación de las ideas en oraciones básicas. Citamos la propuesta de Salvador Gutiérrez Ordoñez, de Roger Hadlich, de Heles Contreras y de La Nueva Gramática de la Lengua Española. En lengua extranjera consideramos la teoría de L. Tesniére, de N. Chomsky.

La teoría funcionalista de Tesniére influye en algunos españoles. El lingüista francés incide en la noción de "función" en sintaxis. Distingue una sintaxis estática (categorías) y una sintaxis dinámica [funciones]. La primera teóricamente está subordinada a la segunda. Ahora bien, la sintaxis estática se ocupa del análisis de la estructura de superficie y se caracteriza por su linealidad; mientras que la sintaxis dinámica analiza el orden estructural, pero considerando a las funciones.

Mediante el análisis de la sintaxis dinámica da cuenta de la actividad del habla, opuesto a la lengua. Describe estas dos operaciones que realizamos todos los 
hablantes: "hablar" y "comprender". Según este lingüista, "hablar es establecer entre las palabras un conjunto de conexiones... Comprender es aprehender el conjunto de las conexiones que unen las palabras" o dicho de otro modo, "hablar una lengua es transformar el orden estructural en orden lineal, e, inversamente comprender una lengua es transformar el orden lineal en orden estructural".

En realidad, aquel lingüista distingue dos planos: el plano del pensamiento de carácter psicológico y lógico, que tiene categorías universales y el plano de la lengua de orden lingüístico y ambas categorías son variables.

Con relación al primer plano, hace referencia al contenido, por lo tanto es abstracto; respecto al segundo plano, hace referencia a la forma y es concreta. Por otra parte, descompone a la lengua considerando su forma interior (abstracta) y su forma exterior (vestimenta fónica abstracta). La forma interior constituye el objeto de estudio de la sintaxis.

En cuanto a la sintaxis estática, coincide con el planteamiento de las categorías tradicionales. Tesniere señala que estas se agrupan en palabras "vacías" y palabras "plenas". Conforman las palabras plenas: el verbo, sustantivo, adjetivo y adverbio; conforman las palabras vacías: los juntivos (conjunciones), traslativos (preposiciones, conjunciones de subordinación. pronombres relativos), índices (personas, artículos) y anafóricos.

Referente a la sintaxis dinámica, esta da cuenta de tres órdenes de fenómenos

${ }^{4}$ C. FUCHS Y P. LE GOFFIC, Introducción a la problemática de las corrientes lingüisticas contemporáneas, Págs. 52. distintos: la conexión, la junción y la traslación, considerados, "los tres grandes núcleos a cuyo alrededor se organizan todos los hechos de sintaxis estructural". Sostiene que en la oración simple sólo interviene la conexión y en la oración compleja, la junción y/o la traslación.

En una oración básica las conexiones unen un término superior (dominante) y un término inferior (subordinante), a través de un rasgo vertical al cual llama stema.

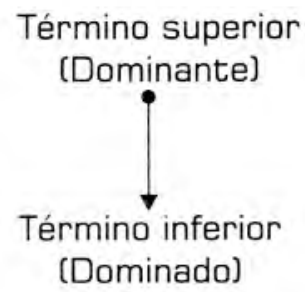

Un término, a su vez, puede estar subordinado a otro término superior y ser dominante de uno inferior. A todo dominante que rige uno o varios subordinados se denomina nudo. "Existen tantas especies de nudos como categorías de palabras plenas. Toda frase implica una disposición particular de uno o varios nudos. El que domina a los otros recibe el nombre de "nudo central". C. Fuchs y $P$. Le Goffic, al respecto señalan: "Esto permite elaborar una tipología de frase según la naturaleza de su nudo central, de allí: la frase verbal, la frase sustantiva, la frase adjetiva y la frase adverbial" ${ }^{4}$.

El verbo es una categoría, al mismo tiempo, una función. Siguiendo los parámetros de Tesniére constituye el núcleo de una oración, en otros términos es el nudo central. Tenemos el verbo /escribió/. Todo lo que se agregue alrededor de él, indica algo. Por ejemplo, 
si se pregunta al verbo, ¿quién escribió? y ¿qué escribió? Las respuestas permiten formar la oración siguiente:

02 Machado escribió Campos de Castilla.

A fin de visualizar los componentes de la oración, se usa el siguiente diagrama:

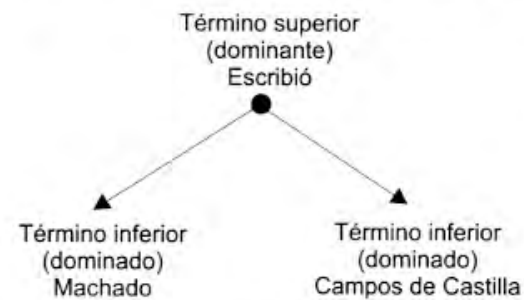

Basado en este modelo de representación, Salvador Gutiérrez propone que la oración básica tiene sujeto, núcleo oracional y complemento. Según su propuesta, la oración de nuestro ejemplo quedaría representada de la siguiente manera:

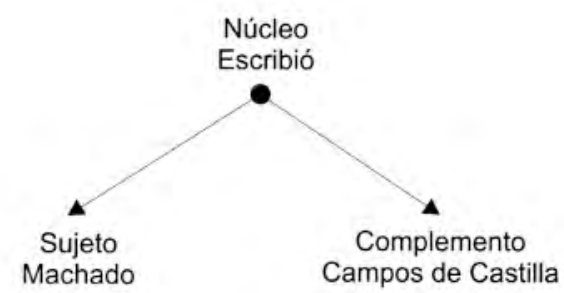

Sustituyendo las funciones expresadas en el esquema anterior por sus respectivas categorías, tal representación es como sigue:

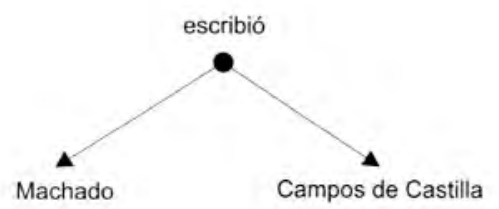

Si representamos a cada término por las categorías sintagmas y considerando a las funciones que desempeñan en la oración, el esquema es el siguiente:

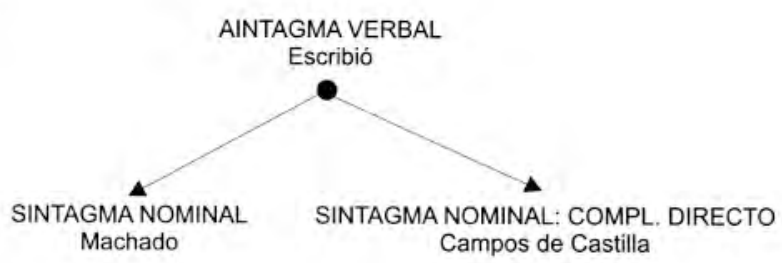

Todas las estructuras lingüísticas con intención comunicativa contienen funciones, relaciones y funtivos. Una idea está conformada por el núcleo oracional, por un sujeto y por uno o más complementos. Dichas funciones, al mismo tiempo, son categorías. El núcleo oracional corresponde a la categoría sintagma verbal; el sujeto, a la categoría sintagma nominal y el complemento nominal a la categoría sintagma adjetivo respectivamente.

Las funciones sintácticas aparecen fusionadas a través de tres tipos de relaciones: coordinación, subordinación e interdependencia.

Los sintagmas son signos simples, complejos, dependientes, autónomos, capaces de contener funciones sintácticas, pero, recuerde, no representan a las ideas básicas. En cuanto a sus límites, estas no se determinan por la extensión o la cantidad de palabras, sino por la función que contrae.

En conclusión, existe cuatro clases de sintagmas: Sintagma verbal (SV), sintagma nominal (SN), sintagma adjetivo [SAdj.) y sintagma adverbial (S Adv.). El sintagma preposicional no es reconocido como una categoría por este modelo, sino como la relación entre una preposición con un sintagma nominal, un sintagma adjetivo o un sintagma adverbial. 


\section{ORGANIZACIÓN DE LAS ORACIONES BÁSICAS}

Teniendo como base la teoría de la sintaxis de la lingüística comunicativa, las ideas se pueden convertir en oraciones, precisando el núcleo oracional que bien puede ser un verbo transitivo o un verbo intransitivo.

\section{La oración con verbo transitivo} necesariamente contiene un objeto directo. Su organización sintáctica requiere seguir las siguientes indicaciones:

Para reconocer el sujeto, la pregunta que se hace al verbo es ¿quién?. Por ejemplo, ¿quién pintó?. La respuesta es el sujeto: Miguel Ángel:

\section{Miguel Ángel pintó.}

Sujeto(quien) verbo

El complemento directo responde a la pregunta ¿qué?, vale decir équé pinto Miguel Ángel?, un paisaje tacneño.

Miguel Ángel pintó un paisaje tacneño.

Sujeto (quién) Verbo Objeto directo (qué)

El complemento indirecto responde a la pregunta ¿para quién?. La pregunta que se formula es el que sigue: ¿para quién pintó Miguel Ángel un paisaje tacneño?

MiguelÁngel pintó un paisajetacneño

Sujeto (quien) verbo objeto directo (qué)

para la Sociedad de Auxilios Mutuos.

objeto indirecto (para quién)

La oración que expresa la esencia de la idea es la que sigue:

03 Miguel Ángel pintó un paisaje tacneño para la Sociedad de Auxilios Mutuos.

Tiene un objeto directo y el verbo que

sPAVÓN LUCERO, María Victoria: Estructura sintáctica en la subordinación adverbial, Pág. 14. funciona como núcleo oracional es transitivo. Una oración básica se escribe siempre sin comas. Sintácticamente está conformada por un sujeto, un verbo, un complemento u objeto directo y un complemento u objeto indirecto.

\section{LA ORACIÓN BÁSICA Y LOS COMPLEMENTOS ACCIDENTALES}

Si a la oración básica que está articulada con sujeto, verbo, objeto directo y objeto indirecto se agrega un circunstancial como complemento del verbo, esta deja de ser esencial. María Victoria Pavón Lucero lo considera como "una clase... de subordinadas circunstanciales" complemento que se agrega es accidental y no esencial. Si a la oración (O3) del ejemplo anterior añadimos, el mes pasado. Responderá a la pregunta, ¿cuándo pintó un paisaje tacneño para la Sociedad de Auxilios Mutuos?, si aún más, agregamos, con el fin de resaltar el aniversario de la ciudad, la interrogante será, ¿̇con qué fin pintó?. Estas construcciones son circunstancias que deben ir separadas con una coma. Por lo tanto, la coma se determina según la estructura de la oración, no importando la extensión.

Miguel Ángel (sujeto (quién)) pintó (verbo) un paisaje tacneño (objeto directo (qué)) para la Sociedad de Auxilios Mutuos (objeto indirecto (para quién)), con el fin de resaltar el aniversario de la ciudad (circunstancial de fin (con qué fin pintó...). La oración correctamente expresada es la que sigue:

Miguel Ángel pintó un paisaje tacneño para la Sociedad de Auxilios Mutuos, con el fin de resaltar el aniversario de la ciudad.

Se observa que sólo el complemento circunstancial [accidental] se separa con coma. 
En una oración básica, la esencia es la que no cambia y se expresa siempre con un sujeto, verbo, complemento directo y complemento indirecto. Nunca se usa coma. Las circunstancias, en cambio, pueden afectar momentáneamente. No son permanentes.

(04) El mesero sirvió las copas a los invitados.

Reiteramos que la oración básica no lleva coma. No se puede escribir coma después de /El mesero/, porque es un error separar un sujeto del verbo. Tampoco existe coma después de/sirvió/, puesto que estaríamos separando el verbo del complemento directo, lo cual no se admite. No se escribe coma después de /copas/, que separaría el objeto directo del indirecto.

Aún cambiando el orden de las palabras en una oración básica, la esencia se escribe sin comas. Obsérvese más ejemplos de oraciones básicas:

(05) Raúl devolvió el dinero a Ruth.

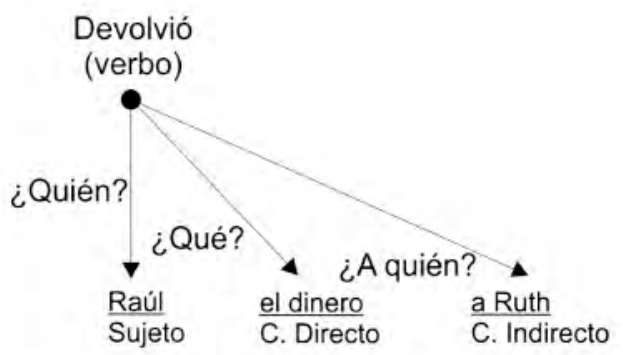

(06) La Empresa Prestadora de Servicios entregó a los usuarios una nueva fórmula de facturación.

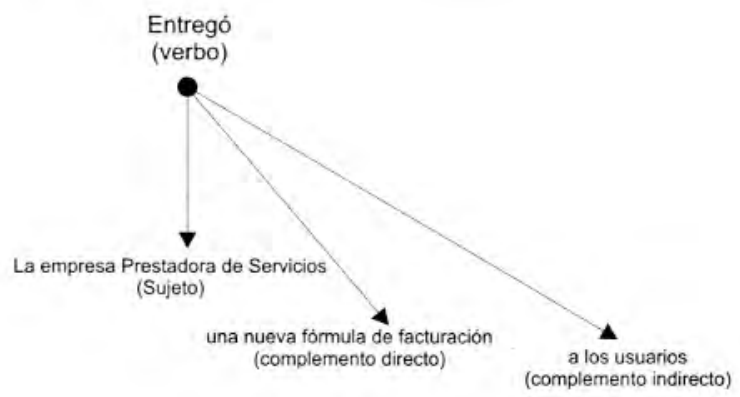

(07) Las señoritas que hayan cursado Inglés básico pueden solicitar su convalidación del curso al Decano de la Facultad de Educación.

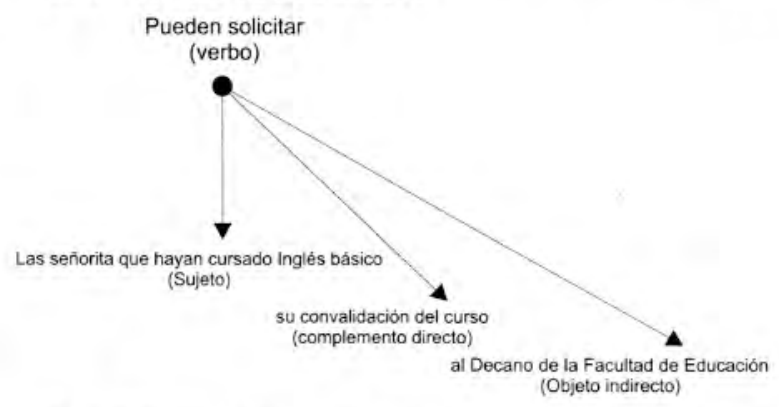

(08) Los griferos anunciaron que habia bajado el precio de la gasolina.

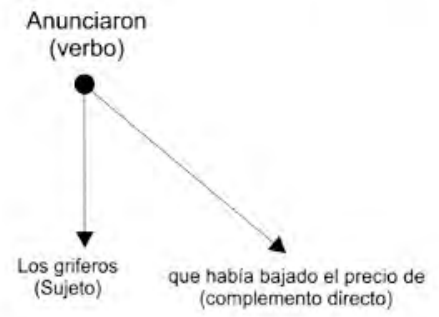

(09) Maria Julia narró risueñamente una historia imaginada.

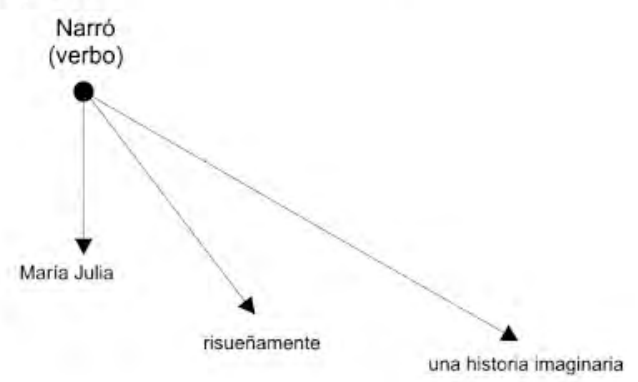

(10) Se utilizó tubos de ensayo

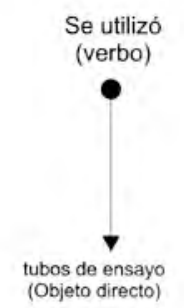

En las oraciones básicas es un error usar coma para separar el sujeto del verbo:

(11) Vladimir Aquino obsequió caramelos a sus alumnos. Sujeto verbo 
Tampoco se usa coma para separar el verbo del complemento directo:

- Vladimir Aquino obsequí, caramelos a su alumnos verbo C. Directo

Nunca se escribe coma entre el complemento directo y el complemento indirecto.

- Vladimir Aquino obsequió caramelos, a sus alumnos.

C. Directo C. Indirecto

Aún cambiando el orden en la estructura sintáctica de las oraciones, la puntuación sigue siendo la misma. Por tanto, no es correcto escribir coma en las siguientes oraciones:

- Vladimir Aquino obsequió caramelos a sus alumnos.

-Obsequió caramelos a sus alumnos Vladimir Aquino.

-A sus alumnos obsequió caramelos Vladimir Aquino.

- Caramelos obsequió Vladimir Aquino a sus alumnos.

La oración ideal que comunica la esencia de la idea, siguiendo el orden lineal que ofrece la sintaxis es la primera de las oraciones, tal como en la siguiente representación:

\begin{tabular}{|c|c|c|c|}
\hline SUETO & VERBO & OBETO DIRECTO & OBETO INDIRECTO \\
\hline - Vladimir Aquino & obsequió & caramelos & a sus alumnos. \\
\hline
\end{tabular}

\section{ORACIONES BÁSICAS CON VERBOS INTRANSITVOS}

Las oraciones básicas con verbo intransitivo no aceptan objeto directo.

(12) Anoche soñé.

(13) Hoycorri.

(14) El próximo año descanso.

(15) Los alumnos están discutiendo
Todas estas oraciones expresan ideas completas, no necesitan de un complemento directo. Los verbos soñé, corrí, descanso, están discutiendo son intransitivos. La oración básica se reduce a un verbo:

(16) Truena.

(17) Está garuando.

(18) Vaya.

Puede que el verbo de la oración tenga algún adverbio:

(19) Truena horriblemente.

(20) Está garuando demasiado.

(21) Vaya rápido.

Algunas oraciones pueden tener sujeto $y$ verbo:

(22) La pequeña Maruja (sujeto) //lloraba (predicado).

(23) Aquel gallo (sujeto) // canta (predicado).

También es oración básica si el verbo tiene complemento que no es directo sino preposicional.

La pequeña Maruja lloraba en brazos de su madre. Aquel gallo canta a media noche.

Se llama complemento preposicional a la construcción que empieza con una preposición (a, ante, bajo, cabe, con, contra, de, desde, en, entre, hacia, hasta, para, por, según, sin, so, sobre, tras].

En conclusión, las oraciones básicas con verbo intransitivo se escriben sin coma y están organizadas por un solo verbo, por un verbo y adverbio y por sujeto, verbo y complemento preposicional.

Los complementos preposicionales no se escriben con comas. La preposición es el elemento que va después del verbo o frase verbal intransitivo:

(24) El profesor habla de politica. 
(25) El profesor habla sobre politica.

(26) El profesor habla sin politica.

En todas estas oraciones no se usan comas para separar el verbo de su complemento preposicional. Son incorrectas las construcciones como estas:

- El profesor habla, de política.

- El profesor habla, sobre política.

- El profesor habla, sin politica.

\section{CONCLUSIONES}

1. Existen teorías de la sintaxis basadas en la lingüística de la comunicación que ayudan a transformar las ideas en oraciones.

2.Las oraciones básicas formalmente están articuladas por sujeto, verbo, complemento directo y complemento indirecto. Expresan una ideas esencial y no llevan comas.

2. El sujeto y el predicado que son los componentes de una oración básica jamás se separan con comas.

3. Se utilizan comas en las oraciones básicas cuando existe una enumeración.

4. Las oraciones básicas con verbo intransitivo tienen como complemento un sintagma preposicional y se escribe sin coma.

5. Atendiendo al orden lógico, en una oración básica con verbo transitivo, el objeto indirecto se escribe después del objeto directo a no ser que sea muy extenso.
8. En una oración con verbo transitivo y que tiene sujeto, verbo, objeto directo, objeto indirecto y complemento circunstancial, este último complemento, por ser accidental, se escriben entre comas.

\section{REFERENCIAS BIBLIOGRÁFICAS}

ALCÁNTARA PLÁ, Manuel: Introducción al análisis de estructuras lingüisticas en corpus. Aproximación semántica, Madrid, Ediciones UAM, 2017

ANTAS, Delmiro: El análisis gramatical, Barcelona, Ediciones OCTAEDRO, S.L., Primera Edición, 2007.

ÁVILA Fernado: Español correcto, Colombia, Grupo Editorial Norma, Primera Edición, 2002.CASSANY, Daniel: Expresión escrita en L2/ELE. Cuaderno de didáctica del español/LE, Madrid, Arco Libros S.L. 2005.

CASADO VELARDE, Manuel: Introducción a la Gramática del Texto del Español, Madrid, Arco Libros S.L., Quinta edición, 2006.

CONTREARS, Heles: El orden de palabras en español, Madrid, Editorial Cátedra, 1978.

CUENCA, Maria Josep: gramática del texto. Cuadernos de Lenguia Española 108, Madrid, Arco Libros S.L., Primera Edición, 2010.

GONZÁLEZ CALVO, José Manuel: La oración simple, Madrid, Arco Libros S.L., Segunda Edición, 1995.

GUTIÉRREZ ARAUZ, María Luz: Problemas fundamentales de la gramática del español 2/L, Madrid, Arco Libros S.L. Tercera Edición, 2011.

GUTIÉRREZ ODÓÑEZ, Salvador y otros: Análisis sintáctico I, Madrid, Edición Grupo Anaya S.A., 2002.

Forma y sentido en sintaxis, Madrid, Arco Libros S.L. Segunda Edición, 2009. HADLICH, Roger L. Gramática transformativa del español. Madrid, Editorial Gredos S.A., 1982.

MARTÍNEZ LIRA, Lourdes: De la oración al párrafo. 
La Vida y la Histaria

México, Editorial Trillas de C.V. Octava reimpresión, 2005.

PAVÓN LUCERO, Maria Victoria: Estructuras sintácticas en la subordinación adverbial, Madrid, Arco Libros S.L., Primera edición, 2012.

REYES, Graciela: Cómo escribir bien en español, Madrid, Arco Libros S.L., Quinta Edición, 2006 REAL ACADEMIA ESPAÑOLA: Nueva Gramática de la Lengua Española, Espasa libros, S.L.U.. 2010, Tlyll.
TOBÓN DE CASTRO, Lucia: Estudios en torno a los procesos de significar y comunicar. Bogotá, Universidad Pedagógica Nacional, Primera Edición, 2001.

Correspondencia Santos Conde Lucero conde_mayo@hotmail.com

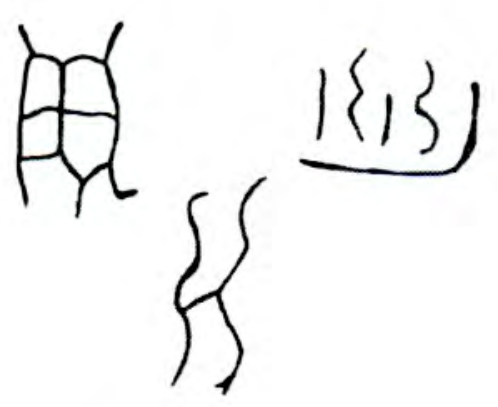

85 